Pesq. Vet. Bras. 31(6):516-520, junho 2011

Tópico de Interesse Geral

\title{
Plantas que causam alterações mecânicas ou traumáticas em ruminantes e equinos, com ênfase em Stipa spp. (Gramineae) ${ }^{1}$
}

\author{
Beatriz Riet-Correa², Gabriela Riet-Correa ${ }^{3}$ e Franklin Riet-Correa ${ }^{2 *}$
}

\begin{abstract}
Riet- Correa B., Riet-Correa G \& Riet-Correa F. 2011. [Plants that cause mechanic or traumatic alterations in ruminants and horses, with emphasis on Stipa spp. (Gamineae).] Plantas que causam alterações mecânicas ou traumáticas em ruminantes e equinos, com ênfase em Stipa spp. (Gramineae). Pesquisa Veterinária Brasileira 31(6):516-520. Hospital Veterinário, Centro de Saúde e Tecnologia Rural, Universidade Federal de Campina Grande, Campus de Patos, 58700-070 Patos, PB, Brazil. E-mail: franklin.riet@pq.cnpq.br

Many plants cause mechanical injury in horses and ruminants, as those that cause traumatism on skin and mucosa, and those that cause lesions in the digestive system, including esophagus obstruction, rumen overload, and intestinal obstruction. In this paper, plants causing mechanical injury to ruminants and horses in Brazil are reviewed, and an outbreak in sheep of mechanical injury of the skin by Stipa sp. in Uruguay is reported. The sheep, mainly lambs, showed large number of fruits of Stipa sp. in the wool, some of them penetrating the skin, panniculus adiposus, and cutaneous trunci muscle, causing multifocal dermatitis and panniculitis.
\end{abstract}

INDEX TERMS: Plants causing mechanical injury, Stipa spp., Aristida spp., Mimosa spp., Xanthium spp., Prosopis juliflora, Stylosanthes spp., ruminants, horses.

RESUMO.- Várias plantas podem provocar algum tipo de injúria mecânica. Entre elas as que causam traumatismo da pele ou mucosas, e as que causam alterações do sistema digestório, incluindo obstrução esofágica, sobrecarga ruminal e obstrução intestinal. Neste trabalho são revisadas algumas plantas que causam essas alterações e é descrito um surto de injúria mecânica causada por Stipa spp. (flechilha) em ovinos no Uruguai. Os animais, principalmente os cordeiros, apresentavam grande quantidade dos frutos de flechilha incrustadas na lã e alguns desses se introduziam na pele, panículo adiposo e músculo cutâneo do tronco causando dermatite e paniculite multifocal difusa.

TERMOS DE INDEXAÇÃO: Plantas que causam lesões mecânicas, Stipa spp., Aristida spp., Mimosa spp., Xanthium spp., Prosopis juliflora, Stylosanthes spp., ruminantes, equinos.

\footnotetext{
${ }^{1}$ Recebido em 20 de dezembro de 2010.

Aceito para publicação em 21 de janeiro de 2011.

2 Hospital Veterinário, Centro de Saúde e Tecnologia Rural (CSTR), Universidade Federal de Campina Grande (UFCG), Campus de Patos, 58700-000 Patos, PB, Brasil. * Autor para correspondência: franklin.riet@pq.cnpq.br

${ }^{3}$ Faculdade de Medicina Veterinária, Universidade Federal do Pará, Rua Maximino Porpino da Silva 1000, Castanhal, PA 68743-080, Brasil-
}

\section{INTRODUÇÃO}

Várias plantas podem provocar algum tipo de injúria mecânica. Entre elas estão as que causam traumatismo da pele ou mucosas, e as que causam alterações do sistema digestório, incluindo obstrução esofágica, sobrecarga ruminal e obstrução intestinal. Neste trabalho serão revisadas algumas plantas que causam essas alterações e descrito um surto de lesões mecânicas em ovinos causado por Stipa spp. no Uruguai.

\section{Plantas que causam alterações mecânicas no sistema digestório}

Obstrução esofágica ocorre esporadicamente em animais que ingerem algumas frutas (laranjas, maçãs, peras, pêssegos, caroços de manga) e tubérculos (beterraba, batata inglesa e batata doce). A doença é mais comum em animais jovens e em raças pequenas como a Jersey (Borges et al. 2010).

A ingestão de grandes quantidades de vagens de Prosopis glandulosa causa compactação ruminal em bovinos e obstrução intestinal em eqüinos (Knight \& Walter 2001). Quadros de compactação ruminal não tem sido observados em ruminantes consumindo vagens de Prosopis juliflora (algaroba) na região Nordeste, porém, eqüinos alimenta- 
dos em áreas invadidas por algaroba podem desenvolver obstrução intestinal causada pela presença de massas indigeríveis formadas pelas vagens da planta (fitobenzoários) (Medeiros et al. 2010).

A ingestão de Dispyros virginiana (caqui), em eqüinos, forma fitobenzoários no estômago que lesam a mucosa gástrica causando úlceras que podem levar a ruptura do órgão (Knight \& Walter 2001). No Brasil apesar dessa planta ser cultivada não há descrição de casos semelhantes.

Cascas de feijão (Phaseolus vulgaris e Vigna unguiculata) e folhas de Licania rigida (oiticica) podem causar compactação ruminal em bovinos no sertão paraibano (Assis et al. 2009). Casos de compactação ruminal ou formação de fitobezoares têm sido observados em bovinos na região Nordeste do Brasil em animais alimentados com o bagaço do sisal (Agave sisalana), produto com muita fibra de baixa digestibilidde que é aproveitado para alimentação animal em épocas de seca prolongada. Gramíneas muito fibrosas e de baixa digestibilidade, como o capim panasco (Aristida sp.) na região nordeste e a palha Santa Fé (Panicum prionitis) no Rio Grande do Sul podem causar, também, compactação ruminal quando os ruminantes as ingerem em épocas de escassez de forragem. A ingestão de Pennisetum purpureum (capim napier, capim elefante) pode causar compactação de cólon maior em eqüinos (Silva Neto 2007, Medeiros et al. 2010) e compactação de abomaso em bovinos (Borges et al. 2007).

A ingestão da leguminosa Stylosanthes spp. (Estilosantes Campo Grande) em proporções superiores a recomendada $(20-40 \%$ da leguminosa no consórcio com gramíneas) pode levar à formação de fitobenzoários e obstrução gastrointestinal em bovinos (Embrapa 2007, Moraes et al. 2010). Na região Nordeste foram descritos casos de obstrução gastrointestinal por fitobenzoários em bovinos alimentados principalmente com Opuntia ficus-indica (palma forrageira) (Afonso et al. 2008).

O cinamomo (Melia azedarach) é descrito na África do Sul como causa de compactação ruminal e obstrução intestinal (Knight \& Walter 2001). No Brasil apesar da abundância da planta no sul do país não tem sido descritos casos.

\section{Plantas que causam injúrias na pele}

Os frutos de Xanthium spp. (carrapicho) causam obstrução e inflamação do prepúcio em bovinos (Kellerman et al. 2005). No Uruguai e no Rio Grande do Sul lesões causadas por Xanthium cavalinessie $X$. spinosum são observadas freqüentemente no prepúcio de touros e também se acumulam na lã de ovinos podendo causar alterações traumáticas, alem das dificuldades para o manejo dos animais e perda do valor da lã.

Lesões ulcerativas e granulomatosas da pele dos membros de bovinos, ovinos (Barbosa et al. 2009a) e equídeos (Barbosa 2010) têm sido observadas no Pará em pastagens invadidas por Mimosa pudica cujos espinhos ferem a pele. Lesões semelhantes são observadas no semiárido brasileiro em bovinos em áreas invadidas por Mimosa pudica e/ou Mimosa debilis (Franklin Riet-Correa, dados não publicados).
No Maranhão e no Pará foram observados equinos com aumento da fenda bucal por lesão na comissura labial. Esses animais recebem a denominação de "boca rasgada" e as lesões foram associadas à ação cortante das folhas de Panicum maximum na comissura labial durante a apreensão da pastagem (Barbosa et al. 2009b).

No Pará foram descritos casos de acúmulo de sementes da palmeira mucajá (Acrocomia aculeata) no vestíbulo oral de búfalos causando atrofia por compressão com adelgaçamento e desvio lateral do osso mandibular (Barbosa et al. 2009c).

Dalechampia sp.(tamiarana) foi citada como causadora de irritação na mucosa oral e da pele em caprinos no Nordeste (Assis et al. 2009).

Opuntia spp. são cultivadas como forragem no semiárido da África do Sul. Em ovinos seus longos espinhos e suas inúmeras cerdas penetram na pele dos lábios e causam danos á boca, esôfago e estômago, principalmente no anel pilórico do abomaso. As cerdas penetram na mucosa e formam pequenos abscessos e granulomas (Kellerman et al. 2005). Apesar de Opuntia fícus-indica ser cultivada como forrageira na região semiárida do Brasil, não tem sido descritas lesões associadas a essa forrageira ou a outras espécies de Opuntia nativas da região.

Na região semiárida do Nordeste podem ocorrer lesões em caprinos e ovinos, causadas por espinhos de plantas cactáceas, como Cereous jamacaru (mandacaru) e Pilosocereus gounellei (xique-xique). Lesões nos cascos de caprinos causadas por espinhos de xique-xique ocorrem quando esses animais permanecem em posição bipodal com os membros anteriores apoiados nos ramos dessa cactácea para ingerir suas flores ou frutos (Pessoa 2010). Lesões nos cascos podem ser causadas pelos espinhos de Zizyphus joazeiro (joazeiro) ou Prosopis juliflora. Numerosos casos de claudicação causados por espinhos de $P$. juliflora tem sido observados em ovinos, principalmente após as chuvas, quando os casos estão amolecidos (Franklin Riet-Correa, dados não publicados).

Frutos de gramíneas com pontas afiadas, incluindo (Stipa spp, Aristida spp. e Heteropogon spp.) se alojam na lã de ovinos e se inserem no tecido subcutâneo, podendo ficar encapsuladas ou causar paniculite ou pequenos granulomas e abscessos (Rosengurtt et al. 1970, Araújo 1972, Vaz et al. 1998, Kellerman et al. 2005) . Esses frutos podem migrar mais profundamente nos músculos, ou até mesmo para a cavidade torácica e abdominal. Em uma ovelha, uma semente de Heteropogon contortus, foi incidentalmente encontrada na válvula átrio ventricular (Kellerman et al. 2005). Sementes e arestas de Tremeda triantra causaram morte em cordeiros lactentes na África do Sul, em consequência de lesões da mucosa oral, especialmente na face, boca e palato causando abscessos por contaminação bacteriana. Frutos de Charis pycnotrix, apesar de serem mais finos e, aparentemente, mais macios e inofensivos, podem causar danos a mucosa oral de ovinos e bovinos alimentados com alfafa moída contaminada por esta gramínea (Kellermann et al. 2005). 
Lesões traumáticas causadas por Stipa spp. e Aristida spp. (flechilhas) no Rio Grande do Sul e no Uruguai

No Uruguai e no Rio Grande do Sul várias espécies de gramíneas invasoras da família Stipae, incluindo Stipa spp., Aristida spp. e Piptochaertium spp., conhecidas como flechilhas, tem um fruto muito pontiagudo e afiado que penetra na pele causando feridas doloridas (Rosengurtt et al. 1970, Araújo 1972, Vaz et al. 1998). Também podem causar conjuntivite, ceratite e cegueira e as lesões podem ser infectadas por Cochliomyia hominivorax (miíases). As flechilhas causam importantes prejuízos devido ao fato de serem encontradas em regiões grandes produtoras de ovinos lanados, onde a venda da pele representa um mercado importante. Os traumatismos deixam seqüelas que persistem durante o processamento dos couros, acarretando perdas para a indústria (Vazet al. 1998). Apesar de que as flechilhas presentes na lã se calcinam durante a industrialização, a presença dos frutos é importante na qualidade desse produto. Alem das perdas com a pele e a lã, há prejuízo também por diminuição do ganho de peso diário devido ao desconforto causado pelas lesões dolorosas ocasionadas pela flechilha, principalmente quando os ovi- nos permanecem sem que seja cortada a lã ao redor dos olhos (Bonino 2010). A flexilha é, também, uma das principais causas de traumatismo dos cascos de ovinos, lesando o espaço interdigital causando inflamação, dor e claudicação (Bonino et al. 2004); ocasionalmente essas lesões se complicam com miíases (Bonino et al. 2010). Quando ovinos com flexilha são banhados em banhos de imersão para o controle de piolho e sarna as feridas causadas pelos frutos podem se infectar causando numerosos abscessos e, às vezes até a morte do animal.

No Uruguai, existem mais de 40 espécies nativas de Stipae (flechilhas), todas perenes, algumas de excelente produção forrageira, cujo cultivo é impraticável devido à agressividade de seus frutos que causam lesões nos animais (Rosengurtt et. al. 2010).

As espécies com frutos mais agressivos são Piptochaertium bicolor, Stipa charruana, S. setigera, S. arechavaletai, S. filicumis, S. juncoides, S. leptocoronata, S. longicoronata, S. longiglumis, S. melanosperma var melanosperma $S$. neesiana var. neesiana, $S$. nutans var. quinqueciliata, S. papposa, S. pauciciliata, S. poeppichiana, S. subnitida, S. torquata, Stipa sellowiana, Stipa methistina,
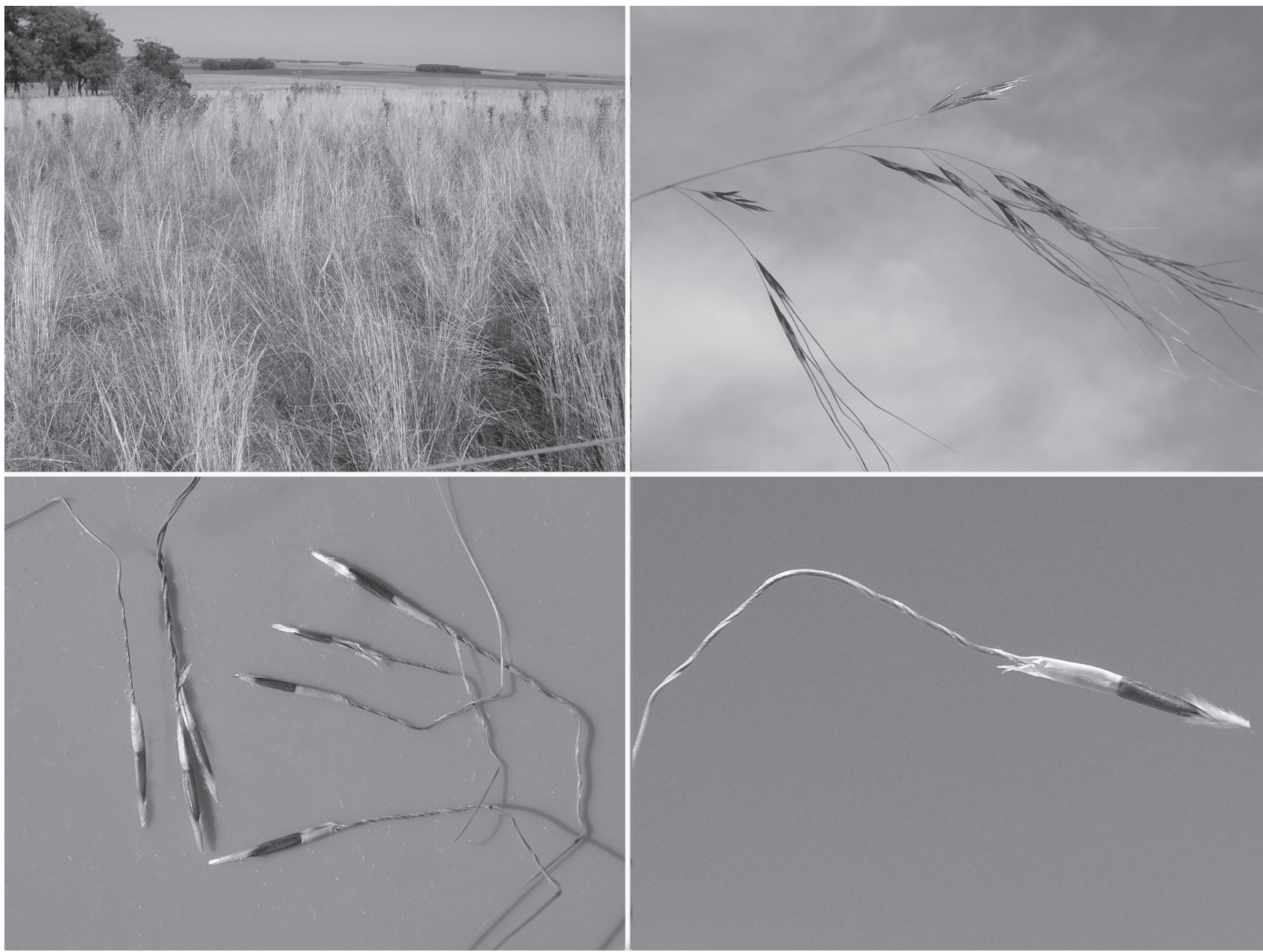

Fig.1. Stipa sp. Departamento de Rocha, Uruguai. 
Stipa hyalina, Aristida murina, A. spegazinii (Rosengurtt et al. 1970, 2010, Araújo 1972), que sementam de dezembro à janeiro causando moléstias para o gado (Rosengurtt et. al. 2010). As espécies de Aristida são designadas como flechilha roxa (Araújo 1972). Segundo Vaz et al. (1998), no Rio Grande do Sul as principais lesões na pele ovina antes do abate, são devidas às flechilhas.

Foi observado, experimentalmente, que cordeiros em campo natural invadidos por Stipa spp. apresentaram maior número de lesões do que cordeiros em campos com pastagens cultivadas invadidas por Stipa spp. (Vaz et al. 1998). Cordeiros da raça Corriedale apresentaram coeficiente de correlação linear negativo entre o número de lesões causadas por flechilhas e o ganho diário de peso, o que não ocorreu em cordeiros da raça Ideal, sob as mesmas condições, sugerindo possível implicação de alguma característica racial (Vaz et al. 1998). Essa característica poderia ser a presença de lã na cara dos animais. Os ovinos da raça Corriedale tem maior quantidade de lã ao redor dos olhos em relação à raça Ideal, acumulando possivelmente mais flechilhas nessa região, podendo causar lesões oculares.

\section{NOSSAS OBSERVAÇÕES}

Em 29 de dezembro de 2009, em uma propriedade localizada no Departamento de Rocha, Uruguai, foi revisado um rebanho da raça Corriedale constituído por 290 ovinos, sendo destes 250 adultos e 40 cordeiros. Os animais permaneciam em pastagem nativa invadida por grande quantidade de Stipa sp. que estava em época de sementação (Fig.1). Os ovinos, principalmente os cordeiros, apresentavam grande quantidade de espinhos em forma de flechas incrustadas na lã; algumas estavam soltas e outras perfuravam a pele, que se apresentava hiperêmica (Fig.2A).

Foi abatido um cordeiro de 4 meses de idade. Ao retirar a pele havia grande quantidade dos frutos incrustados no panículo adiposo e músculo cutâneo do tronco com áreas hemorrágicas e formação de nódulos (Fig.2B). A parte inter-
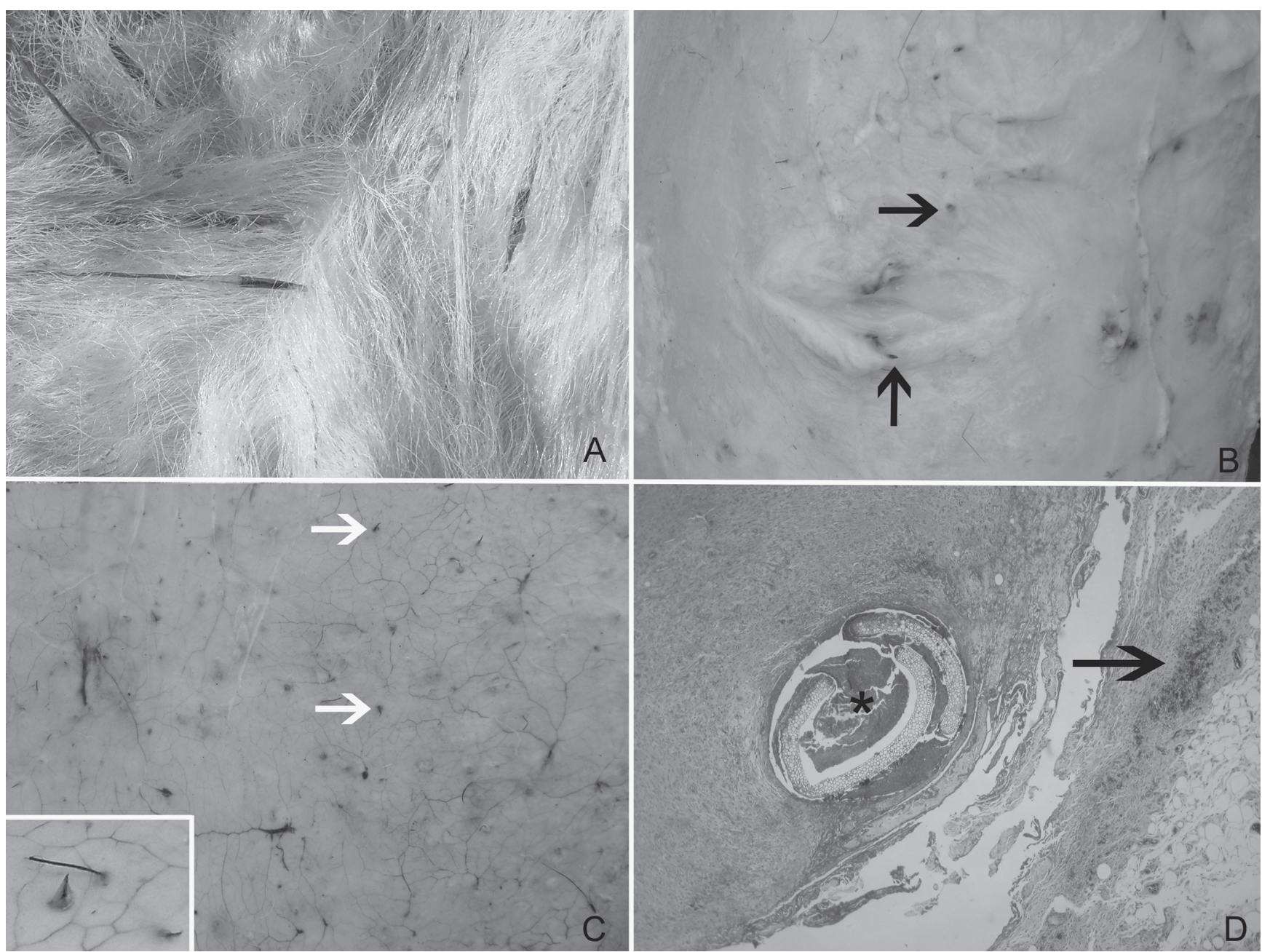

Fig.2. (A) Diversas frutos de Stipa sp. entremeados na lã de ovino. (B) Panículo adiposo e músculo cutâneo do tronco com nódulos e hemorragias multifocais e presença de frutos de Stipa sp. (setas). (C) Parte interna da pele com severa congestão, hemorragias e presença de numerosos frutos de Stipa sp., atravessando a pele (setas). (D) Corte histológico de nódulo causado por Stipa sp. Observa-se material vegetal no centro $\left(^{*}\right)$ rodeado de tecido conjuntivo infiltrado com células inflamatórias e presença de hemorragias (seta). 
na da pele estava difusamente hiperêmica, com inúmeras sufusões (Fig.2C) e frutos de flechilhas atravessando a mesma (Fig.2C). As lesões estavam localizadas principalmente na região do abdômen e flanco. As lesões histológicas do animal abatido consistiram em paniculite e dermatite multifocal difusa, hemorrágica, com presença de material vegetal rodeado por células inflamatórios necróticas e infiltrado inflamatório, principalmente de neutrófilos, envolvidas por tecido conjuntivo fibroso (Fig.2D). Dentro do tecido fibroso, nas proximidades do tecido vegetal, havia infiltração de neutrófilos, plasmócitos e macrófagos. Numerosas hemorragias, com diferentes extensões, eram observadas perto do material vegetal. Ocasionalmente havia tecido fibroso envolvendo feixes musculares que apresentavam fibras degeneradas homogeneamente eosínofílicas.

Algumas práticas de manejo podem ser utilizadas para diminuir a incidência de lesões causadas por flechilhas nos ovinos, principalmente em cordeiros que devem permanecer durante os meses de dezembro e janeiro em campos sem ou com pouca flechilha. A sementação massiva das flechilhas pode ser evitada mediante pastejo intensivo antes da sementação ou mediante passagem da roçadeira. Em anos chuvosos, provavelmente pela maior disponibilidade de forragem, a flechilha é mais numerosa. O pastejo exclusivo de ovinos é mais favorável á presença das diferentes espécies de flechilhas do que o pastejo misto de ovinos e bovinos (Formoso \& Pereira 2008). Em fazendas com alta frequência de flechilha, os ovinos, principalmente os cordeiros, devem ser tosquiados (esquilados) antes da sementação e caso o rebanho não seja tosquiado deve ser feito o corte da lã ao redor dos olhos.

Agradecimentos.- Este trabalho foi financiado pelo Conselho Nacional de Desenvolvimento Científico e Tecnológico para o Controle das Intoxicações por Plantas (CNPq, Proc.573534/2008-0). O primeiro autor agradece à CAPES pela concessão de bolsa de doutorado.

\section{REFERÊNCIAS}

Afonso J.A.B., Pereira A.L.L., Vieira A.C.S., Mendonça C.L., Costa N.A. \& Souza M.I. 2008. Alterações clínicas e laboratoriais na obstrução gastrintestinal por fitobezoários em bovinos. Revta Bras. Saúde Prod. Anim. 9(1):91-102.

Araújo A.A. 1972. Melhoramento das pastagens. $3^{\text {a }}$ ed. Editora Sulina, Porto Alegre. 187p.

Assis T.S., Medeiros R.M.T., Araújo J.A.S., Dantas A.F.M. \& RietCorrea F. 2009. Intoxicações por plantas em ruminantes e eqüídeos no Sertão Paraibano. Pesq. Vet. Bras. 29(11):919-924.

Barbosa J.D., Silveira J.A.S., Albernaz T.T., Silva N.S., Reis A.S.B., Oliveira C.M.O., Riet-Correa G. \& Duarte M.D. 2009a. Lesões de pele causadas pelos espinhos de Mimosa pudica (Leg. Mimosoideae) nos membros de bovinos e ovinos no estado do Pará. Pesq. Vet. Bras. 29(5):435-438.

Barbosa J.D., Albernaz T.T., Riet-Correa G., Cerqueira V.D., Soares S.O., Campos K.F., Oliveira C.M.C. \& Duarte M.D. 2009b. Queilite angular traumática em eqüinos associada a ingestão de Panicum maximum. Pesq. Vet. Bras. 29(5):428-430.

Barbosa J.D., Amaral Jr J.M., Pinheiro C.P., Oliveira C.H.S., Oliveira C.M.C., Souza M.G.S. \& Duarte M.D. 2009c. Acúmulo de sementes de Acrocomia aculeata (Arecaceae) na bochecha de búfalos no Pará. Pesq. Vet. Bras. 29(5):431-434.

Bonino J. 2010. Comunicação pessoal. Secretaria Uruguaya de la lana. Montevideo, Uruguay. E-mail: jbm@adinet.com.uy

Bonino J., Casaretto A., Castells D., Pereira D. \& Scremini P. 2004. Traumatismos, p.24-40. In: Ibid. (Eds), Livro de Sanidad Ovina. Sul, Montevideo. 90p.

Borges J.R.J., Cunha P.H.J., Moscardini A.R.C., Tortelly R., Franco G.L. \& Silva L.A.F. 2007. Compactação de abomaso em bovinos leiteiros: descrição de cinco casos. Ciênc. Anim. Bras. 8(4):859864.

Borges J.R.J., Moscardini A.R.C. \& Fonseca E.F. 2010. Emergência em ruminantes: o que fazer? Hospital Escola de Grandes Animais da Granja do Torto, Faculdade de Agronomia e Medicina Veterinária, Universidade de Brasília. 5p.

Embrapa 2007. Uso correto do estilosantes-campo-grande em pastagens consorciadas. Nota Técnica, Embrapa Gado de Corte, Campo Grande,MS. <http://www.cnpgc.embrapa.br/NotaTecnica Estilosantes.pdf> Acessado em 1 dez. 2010.

Formoso D. \& Pereira D. 2008. Efecto del pastoreo mixto sobre la vegetación del campo natural em Cristalino Central (Región CentroSur). Producción Ovina 20:5-20.

Kellerman T.S., Coetzer J.A.W., Naudé T.W. \& Botha C.J. 2005. Plant Poisonings and Mycotoxicoses of Liverstock in Southern Africa. $2^{\text {nd }}$ ed. Oxford University Press, Cape Town. 309p.

Knight A.P. \& Walter R.G. 2001. A Guide to Plant Poisoning of Animals in North America. Teton New Media., Jackson, WY, USA. 367p.

Medeiros J.M.A., Miranda Neto E.G., Assis A.C.O., Medeiros J.M., Silva T.R., Nóbrega Neto P.I. \& Lima S.M. 2010. Estudo retrospectivo de casos de síndrome cólica diagnosticadas no Hospital Veterinário da UFCG, Patos, PB. Anais IV Simpósio Abraveq Nordeste, Porto de Galinhas, PE, p.64.

Moraes L.G., Caldeira J.E.B., Ubiali D.G., Linhares R.N.V.D., Lodi L.R.L., Pescador C.A. \& Colodel E.M. 2010. Obstrução intestinal por fitobezoários em bovinos sob pastagem de Stylosanthes sp no estado de Mato Grosso. VI Endivet, Campo Grande, MS. (CD-ROM)

Pessoa C. 2010. Comunicação pessoal (Hospital Veterinário, CSTR, Universidade Federal de Campina Grande, Patos, PB. E-mail: clarice_vet@ig.com.br)

Rosengurtt B., Arrilaga de M. \& Artuccio I. 1970. Gramíneas Uruguayas. Departamento de Publicaciones y Ediciones, Universidad de La República, Montevideo. 492p.

Rosengurtt B., Puerto O., Manffei B.A., Lombardo A. \& Grun S. 2010. Gramíneas. Curso de Botánica, Departamento de Biologia Vegetal, Facultad de Agronomia, Universidad de La República. 7ํㅡㄹ Reimpressão. $112 p$.

Silva Neto P.C. 2007. Relato de caso clínico: compactação de colon maior causada pela ingestão de capim napier. Monografia, Faculdade de Jaguarina, SP. <http://www.equalli.com.br/upload/textos/pdf/ prt/125.pdf>

Vaz C.M.S.L., Muniz E.N., Borba M.F.S. \& Oliveira O.L.P. 1998. Incidência de lesões na pele de cordeiros Corriedale e Ideal causadas por flechilha (Stipa sp.). Anais 35 $5^{\mathrm{a}}$ Reunião Anual da Sociedade Brasileira de Zootecnia, Botucatu, SP, p.34-36. 